\title{
Comment on: Optimisation of intravitreal injection technique using a Barraquer speculum with solid flat blade and finger stabilisation
}

\author{
Salman Waqar ${ }^{1}$ \\ Received: 20 September 2018 / Accepted: 10 October 2018 / Published online: 24 October 2018 \\ (c) The Royal College of Ophthalmologists 2018
}

I read with interest the elegant technique of stabilising the globe during intravitreal injections by Wilde et al. [1]. As part of a local NHS innovation pathway, our team has been working on an intravitreal injection guide which allows for similar stabilisation, while also eliminating the need for a drape and speculum.

The Intravitreal Injection Guide (BVI Malosa) consists of a triangular base plate which is curved to follow contour of the eye and has three studs at the corners for stabilisation of the globe. Its apex is placed at the limbus. The base plate is connected to a cylindrical chamber, which in turn is connected to a handle and a lash guard. The lash guard effectively splays lashes away from the site of injection and the injection needle, and the cylindrical chamber allows $7 \mathrm{~mm}$ of a $13 \mathrm{~mm} / 30$ gauge needle to enter the eye. Once base plate is firmly placed on the surface of the eye, the chamber will only allow the injection to be delivered $4 \mathrm{~mm}$ from the limbus, and perpendicular to the sclera. Concerns have been raised about risk of particulate entry into the eye from plastic linings of needle chambers. To negate this, a metal swage tube has been incorporated into the chamber (Fig. 1).

To evaluate the device's performance, 68 patients received an intravitreal injection (with informed consent) using the guide after local Clinical Effectiveness Group approval. $0.5 \%$ Proxymetacaine drops were instilled, followed by $5 \%$ Povidone-Iodine to the lashes/conjunctival sac prior to injection. Follow up was at 4 weeks.

No complications were noted, and the device was found to stabilise the globe well, even in very mobile eyes, without transmitting lid movement. All patients gave positive feedback particularly with regards to elimination of drape and speculum. Results are summarised in Table 1.

Salman Waqar

salman.waqar@nhs.net

1 Royal Eye Infirmary, Derriford Hospital, University Hospitals Plymouth NHS Trust, PL6 8DH, Plymouth, UK

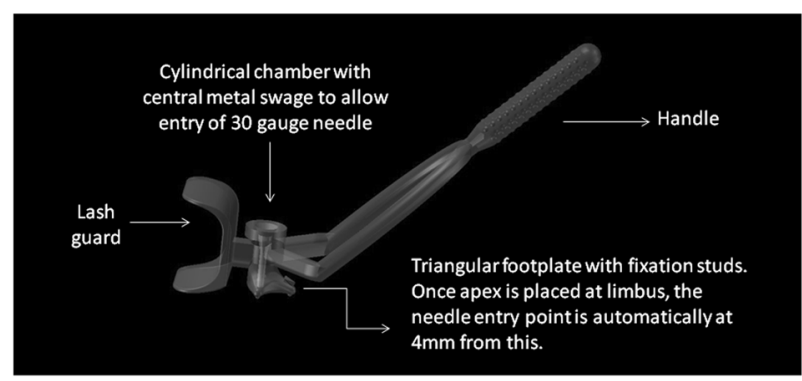

Fig. 1 Design of the intravitreal injection guide

Table 1 Results

\begin{tabular}{|c|c|c|c|c|c|c|}
\hline \multirow{2}{*}{$\begin{array}{l}\text { Age in } \\
\text { years } \\
\text { (Mean) }\end{array}$} & \multirow{2}{*}{ Gender } & \multirow[t]{2}{*}{ Laterality } & \multirow[t]{2}{*}{ Lenticular status } & \multirow{2}{*}{$\begin{array}{l}\text { Complications } \\
\text { (corneal abrasion/ } \\
\text { lens touch/retinal } \\
\text { detachment/ } \\
\text { endophthalmitis) }\end{array}$} & \multicolumn{2}{|c|}{ VA (logMAR) } \\
\hline & & & & & $\begin{array}{l}\text { Pre- } \\
\text { treatment } \\
\text { (Mean) }\end{array}$ & $\begin{array}{l}4 \text { weeks } \\
\text { post } \\
\text { treatment } \\
\text { (Mean) }\end{array}$ \\
\hline 78 & $\begin{array}{l}\text { Male }=48 \% \\
\text { Female }= \\
52 \%\end{array}$ & $\begin{array}{l}\text { Right }= \\
51 \% \\
\text { Left }=49 \%\end{array}$ & $\begin{array}{l}\text { Phakic }=69 \% \\
\text { Pseudophakic }= \\
31 \%\end{array}$ & Nil & 0.33 & 0.32 \\
\hline
\end{tabular}

Medications used were: 55\% Ranibizumab, 43\% Aflibercept, and 2\% Bevacizumab. Indications were: vein occlusion, diabetic retinopathy, or choroidal neovascular membrane

The guide has been developed as part of a unique NHS innovation pathway, meaning revenue generated from its use will be re-directed to improve patient care in our macula service. It is our hope that it will be useful in difficult cases, particularly in the hands of ophthalmic nurse practitioners.

\section{Compliance with ethical standards}

Conflict of interest The authors employing trust (University Hospitals Plymouth NHS Trust) is in a revenue share agreement with BVI Malosa.

\section{References}

1. Wilde C, Awad M, Ross A, Poostchi A, Amoaku W. Optimisation of intravitreal injection technique using a Barraquer speculum with solid flat blade and finger stabilisation. Eye. 2018;32:1413-14. 